detailed color Doppler echocardiography including carotid vessels has been performed Newborns from mothers with bad eating habits had significantly higher values of the right carotid artery intima-media thickness/CAIMT/(p=0.046). Oral health was examined with DMF index/Decayed, Missing, Filled/. A significant correlation between the diameter of the right coronary artery and the DMF index was proven, where the pregnant woman had better diameters with the smaller DMF Index (rho $=-0.693, \mathrm{p}=0.047$ ). CAIMT had a moderate connection with nutrition intake on both of the carotids, whereby the thicker intima had a pregnant woman with poor eating habits (rho $=-0.492, \mathrm{p}=0.03$ ). There was a statistically significant difference in the diameter of descending aorta, with larger diameters in children whose mothers had bad eating habits $(p=0.021)$. Flow over AP was better in newborns from mothers with good eating habits $(p=0.039)$. Fraction shortening/FS\%/was significantly higher in newborns whose mothers had a larger DMF index $(\mathrm{p}=0.03)$. There was a significant correlation of LVEDs/left ventricle end-diastolic diameter/and mothers eating habits (rho $=-0.415, \mathrm{p}=0.044$ ), whereby a higher value LVEDs determined in infants whose mothers had worse eating habits Dietary eating habits and oral health of pregnant women have a significant connection with some segments of cardiovascular system development. Eating habits have an impact on the diameter of blood vessels and on flow.

Unhealthy dietary plans will most probably lead to bad oral health and the presence of periodontitis, which could contribute to the CAIMT and the development of atherosclerosis. It is necessary to extend the study and test inference on a larger sample.

\section{FAMILIAL HYPERCHOLESTEROLEMIA: A RARE CASE OF EARLY DIAGNOSIS}

Ekaterina Dubonosova*, Anastasia Lamasova, Elizaveta Leonova, Alina Pankova, Kamilla Efendieva. Research Institute of Pediatrics and Child Health CCH RAS, Ministry of Science and Higher Education

\subsection{6/archdischild-2021-europaediatrics.26}

Familial hypercholesterolemia (FH) is a common life-threatening genetic condition that causes high cholesterol and leads to a much higher-than-normal risk of coronary heart disease (CHD). The heterozygous type is found in about 1 out of $300-500$ people, the homozygous type is quite rare in 1 out of 1 million people.

Objective To analyze the clinical case of family hypercholesterolemia in sibs.

Patients and Methods In 3 siblings (from triplets) at the age of 7 years randomly detected new-onset hypercholesterolemia $5.97 \mathrm{mmol} / \mathrm{L}, 5.65 \mathrm{mmol} / \mathrm{L}, 6.43 \mathrm{mmol} / \mathrm{L}$. In a second study after 14 days, hypercholesterolemia persists $(6.11 \mathrm{mmol} / \mathrm{L}$, $5.67 \mathrm{mmol} / \mathrm{L}$ and $6.49 \mathrm{mmol} / \mathrm{L}$, respectively). Two siblings (identical) had high cholesterol levels $(4.060 \mathrm{mmol} / \mathrm{L}$ and $4.413 \mathrm{mmol} / \mathrm{L}$ ) due to low density lipoprotein (LDL). The third child with the lowest level of hypercholesterolemia had normal LDL and a high level of high density lipoprotein (HDL). No evidence of secondary hypercholesterolemia (diabetes mellitus, chronic renal insufficiency, hypothyroidism, cholestatic hepatitis, iatrogenic illness) was found.

A mother (42 years old), sticks to a strict diet with a reduced fat content, but hypercholesterolemia persists, statins therapy is not conducted, recommendations for examining children have not been received.

Results Plasma LDL cholesterol level of $4.0 \mathrm{mmol} / \mathrm{L}$ or higher in follow-up blood test, provided parents with hypercholesterolemia, confirms the $\mathrm{FH}$ in two children from triplets.

At the same time, there are no external physical signs of the disease in children (xanthomas, corneal arch, xanthelasma). This, along with relatively low hypercholesterolemia, suggests a prognostically favorable Heterozygous Familial Hypercholesterolemia. Genetic screening for the presence of $\mathrm{FH}$ is not required to confirm the diagnosis, but may be useful if the diagnosis is ambiguous.

A strict diet with a reduced fat content was recommended to patients, as well as supervision of a cardiologist and lipid screening. It was decided that at the age of 8-10 years, while maintaining LDL cholesterol $>4.0 \mathrm{mmol} / \mathrm{l}$ in follow-up blood test would be observed even on the recommended diet, the treatment with low doses of statins wiould be discussed.

Conclusion Despite the prevalence of $\mathrm{FH}$ and the availability of effective treatment, $\mathrm{FH}$ is rarely diagnosed in children. This emphasizes the importance of lipid screening in childhood and cascading screening of all members of the patient's family for the prevention of CHD.

\section{ANTHROPOMETRIC DIMENSIONS OF THE ARAL SEE REGION (KARAKALPAKSTAN, REPUBLIC OF UZBEKISTAN) NATIVES MAY REFLECT NEGATIVE INFLUENCE OF PESTICIDE ENDOCRINE DISRUPTOR CHEMICALS ON THE POSTNATAL ONTOGENESIS}

Andrey P Pugovkin*, Valeriy O Yerkudov, Azat T Matchanov, Kenjabek U Rozumbetov, Ruslan K Dauletov, Sanovar P Esemuratova, Sergey A Lytaev. St.Petersburg State Pediatric Medical University, Department of human physiology

\subsection{6/archdischild-2021-europaediatrics.27}

The aim of the study was revelation of the specific tendencies of the physique development in subjects born and grown up at various distances from the former Aral Lake disaster (ALD) as a possible factor determining exposure window of organochlorine pesticides (OCPs) during the body growth. ALD was a combined result of essential climate aridization and anthropogenic pollution with the excessive application of OCPs in a droughty agricultural region.

A complex anthropometric study including measurement of body mass and length, the size of extremities, pelvis and of skinfold thickness was carried out on 310 volunteers of both sexes. All of them had been born in 1990 - 1995 before the start of effective measures for liquidation of the ALD consequences. The volunteers were divided into three groups, attached to geographical zones: first - zone of ALD, northern part of the region around the town of Muynak; second zone, relatively safe - central part, around the city of Nukus; third zone, safe - the southern part of the region.

The comparison of anthropometric parameters was statistically measured using Kruskal-Wallis test and Mann-Whitney criterion including Bonferoni correction for multiple comparison.

Males from the first group possessed statistically valuable lower body mass, arm length, size of the chest and major joints, waist perimeter, skinfold thickness in comparison to subjects from other groups. In contrast, females from the 
second group possessed higher values of all parameters in comparison to those from the first and the third groups.

Lesser development of bone tissue revealed by a decreased arm length and size of the major joints probably reflect the anti-androgenic effect of OCPs before and during puberty in males of the first group, while the opposite trend revealed in females from the second group may result from estrogenic effect of mild doses of OCPs. Differences in body mass, waist perimeter and skinfold thickness possessed by volunteers from regions with different environmental conditions may reflect the previously described influence of endocrine disruptor chemicals, such as OCPs, on the balance of leptin, whose functions are established in puberty.

\section{FEVER PHOBIA IN CROATIAN FEVER PHOBIA IN CROATIAN PARENTS - WHAT DO THEY KNOW, BELIEVE AND DO WHEN DEALING WITH A FEBTILE CHILD?}

Borna Biljan*, Sanja Dorner. University of J. J. Strossmayer, Faculty of Medicine; Clinical hospital centre Osijek, Department of pe

\subsection{6/archdischild-2021-europaediatrics.28}

The primary goal of this research was to get some insight into knowledge, beliefs and practices of Croatian parents of febrile children. Are they prone to spontaneous reactions caused by an exaggerated fear of fever? To investigate the extent of their 'fever phobia', there was a need to ascertain the duration and the height of child's fever at which parents decided to consult their paediatrician, as well as what possible complications parents associated with high fever. The aim of this study was also to compare beliefs, practices and the sources of information concerning fever management according to the level of the parents' education and the number of their children.

Parents of 64 febrile children visiting primary paediatrician were interviewed using an anonymous questionnaire with fever-related questions, comprising fever management.

Most parents, $70 \%$ of them, claim that high fever is not harmful if treated properly. Children were taken to a paediatrician with fever of $39.1^{\circ} \mathrm{C}$ by $45 \%$ of parents. Although the aforementioned temperature is deemed dangerous by as much as $67 \%$ of parents questioned, the less educated parents were more prone to visit the paediatrician even at lower temperatures. Even more worryingly, 33\% of all questioned parents came to the paediatrician in under 24 hours of fever's onset. It should be noted that some of the more educated parents listed more severe possible complications such as brain damage and death of the child; while on the other hand, lowering of the child's immunity worried more the less educated parents. Even the sources of information on fever management, apart from paediatricians, varied among parents, with educated parents additionally consulting internet sources in contrast to less educated parents who preferred the pharmacist's advice. No significant difference in parental fever management was observed according to the number of children in the household.

It seems that the proper treatment of fever with children is still insufficiently known to most Croatian parents. The 'fever phobia' could cause dilemmas regardless of the level of education of parents who then turn to their health providers for additional advice. The later might deepen the confusion, due to the lack of uniform guidelines and practice for antipyretic treatment of children, especially preschool ones. Further research in this field could lead to better understanding of the problem and possible creation of Croatia's paediatric guidelines for antipyretic therapy of the febrile child.

\section{WHEN ONLY BIOPSY CAN PROVIDE AN ANSWER}

Ana Rita Curval*, Beatriz Vieira, Juliana da Silva Cardoso, Maria José Dinis. Pediatrics Department, UAG da Mulher e da Criança, Centro Hospitalar Universitário de São João, Porto

\subsection{6/archdischild-2021-europaediatrics.29}

Introduction Peripheral lymphadenopathy in children is generally benign and self-limited. However, it can be a manifestation of serious underlying disease, so differential diagnosis is essential.

Case Report We report a case of a 4-year-old male, previously healthy, presented to the paediatric emergency department with a painless right cervical tumefaction, with about one month of evolution. Fever and weight loss were denied, as well as previous illness and contact with cats. Two antibiotic therapy cycles were performed previously, due to likely bacterial infection, without showing clinical improvement.

On physical examination: Good overall appearance. Rosy faced and hydrated.

Right cervical tumefaction $(5 * 3 \mathrm{~cm}$, painless to palpation, without local inflammatory signs). Without other palpable lymphadenopathies or hepatosplenomegaly.

Laboratory tests revealed: hemoglobin 11,8g/dL; neutrophil series count $8,74 \times 109 / \mathrm{L}$; platelet count 376 x109/L; no changes in kidney and liver function; C-reactive protein and Erythrocyte sedimentation rate were negatives.

Due to the persistence of tumefaction, hospitalization was decided for etiological investigation. Serological tests for HIV, CMV, Toxoplasmosis and Bartonella henselae were all negative. Tuberculin skin testing was negative.

Chest radiograph showed no changes. Abdominal ultrasonography with two lymphadenopathies of 11 and $15 \mathrm{~mm}$ in retroperitoneal space, without hepatoesplenomegaly. Cervical ultrasonography revealed a hypoecoggenic nodular image of regular and well-defined contour in the right jugulo-digastric chain, measuring $41 \mathrm{mmx} 16 \mathrm{~mm}$, and showing no adipose hilum, suggesting lymphadenopathy. Aditionally, there were other smaller lymphadenopathies.

Although studies have suggested a benign etiology, due to persistence of tumefaction, a biopsy of the lesion was performed and indicated Burkit Lymphoma.

Conclusion With this work, the authors intend to highlight that if after four weeks of observation and/or empiric therapy, the diagnosis remains uncertain and the lymph node has not regressed in size, a biopsy should be warranted, as only this can confirm or exclude for sure a diagnosis.

\section{A CLINICAL CASE OF A NO EVIDENCE-BASED MEDICAL TREATMENT OF CYTOMEGALOVIRUS INFECTION IN AN INFANT}

Elizaveta Leonova*, Alina Pankova, Anastasia Lamasova, Ekaterina Dubonosova, Anna Alekseeva, Elena Vishneva, Leyla Namazova-Baranova. The Research Institute of Pediatrics and Child Health of the Central Clinical Hospital of the Russian Academy of Sciences of the Ministry of Science and Higher Education of the Russian Federation

10.1136/archdischild-2021-europaediatrics.30 